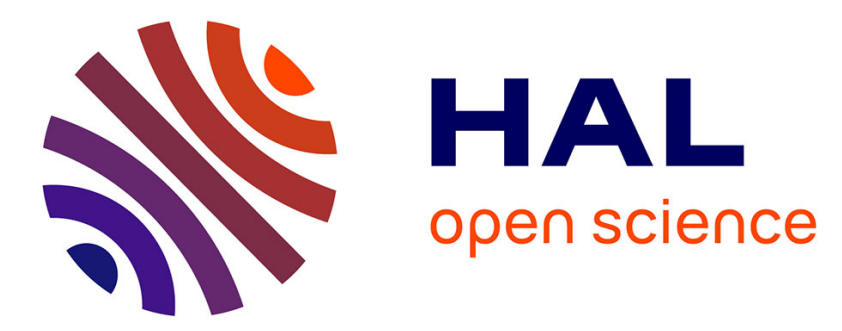

\title{
Production Cost Analysis and Production Planning for Plant Factories Considering Markets
}

Nobuhiro Sugimura, Koji Iwamura, Nguyen Quang Thinh, Kousuke Nakai, Seisuke Fukumoto, Yoshitaka Tanimizu

\section{To cite this version:}

Nobuhiro Sugimura, Koji Iwamura, Nguyen Quang Thinh, Kousuke Nakai, Seisuke Fukumoto, et al.. Production Cost Analysis and Production Planning for Plant Factories Considering Markets. IFIP International Conference on Advances in Production Management Systems (APMS), Sep 2015, Tokyo, Japan. pp.532-540, 10.1007/978-3-319-22756-6_65 . hal-01417607

\section{HAL Id: hal-01417607 \\ https://hal.science/hal-01417607}

Submitted on 15 Dec 2016

HAL is a multi-disciplinary open access archive for the deposit and dissemination of scientific research documents, whether they are published or not. The documents may come from teaching and research institutions in France or abroad, or from public or private research centers.
L'archive ouverte pluridisciplinaire HAL, est destinée au dépôt et à la diffusion de documents scientifiques de niveau recherche, publiés ou non, émanant des établissements d'enseignement et de recherche français ou étrangers, des laboratoires publics ou privés. 


\title{
Production Cost Analysis and Production Planning for Plant Factories Considering Markets
}

\author{
Nobuhiro Sugimura ${ }^{1}$, Koji Iwamura ${ }^{1}$, Nguyen Quang Thinh ${ }^{1}$, \\ Kousuke Nakai $^{1}$, Seisuke Fukumoto ${ }^{1}$ and Yoshitaka Tanimizu ${ }^{1}$ \\ ${ }^{1}$ Graduate School, Osala Prefectuture University, Sakai, Japan \\ sugimura@me.osakafu-u.ac.jp
}

\begin{abstract}
Much emphasis is now given to development of fully closed and controlled plant factories, aimed at supplying various vegetables safely and constantly. However, one of the most important issues of the plant factories is the high production costs due to the investment and equipment in the factories and the daily operations. Systematic methods are considered here increase the delivery prices of the vegetables and to reduce the running costs in the plant factories.
\end{abstract}

Keywords. Plant Factories, Prodction Planning, Cost Analysis

\section{Introduction}

Much emphasis is now given to development and application of fully closed and controlled plant factories, aimed at supplying various vegetables safely and constantly. Many plant factories have been equipped and operated in suburban areas and downtowns for supplying the safe and high quality vegetables directory to the markets $[1,2]$. However, one of the most important problems of the plant factories to be solved is the production costs due to the investment and equipment in the factories and the daily operations. A mathematical model is proposed in the research to estimate the production costs of the vegetables due to the investment, equipment and operations, based on the production conditions of the vegetables and their production volumes in the plants. The proposed model are verified by comparing the estimated production costs by the proposed model with ones of the real plant equipped in Osaka Prefecture University [3].

A production planning method is proposed to select a suitable production plans of the vegetables to be cultivated in the daily operations of the plant factories referring to the forecasting model developed to estimate the market prices of the vegetables. The market prices are forecasted by applying a GP (Genetic Programming) model representing the relationships between the market prices and the weather data.

An electric power supply market is also disscussed to get the electric power for the plant factories, aimed at reducing the electricity costs, since the plant factory requires large amount of electric power for the lighting sources and the air conditioning equipment. 


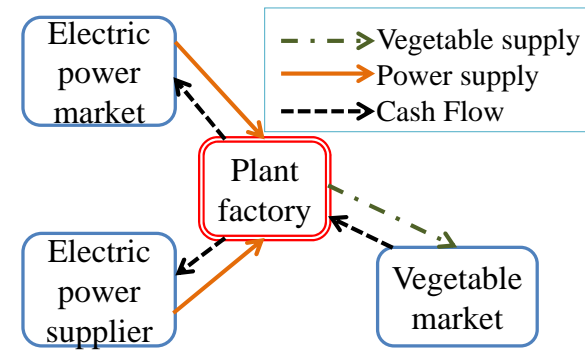

Fig. 1. Vegetable market and electric power market

\section{Plant Factories and their Markets}

Plant factories are production systems which constantly produces safe and high quality vegetables rapidly and constantly. However, the production costs in the plant factories are higher than the ones of the conventional farms, due to initial investment costs including plant constructions, air conditioning equipment, lighting devices and produciton equipment and also running costs for electirc power supply. Therefore, two markets are considerd in the research to reduce the operarion costs and to increase the selling prices of the produced vegetables.

Figure 1 shows the vegetable markets and the electirc suppliers related with the plant factories. The vegetable markets are the markets dealing with the vegetables produced by both the conventional farms and the plant factories, and the market prices are determined based on the supplies and the demands in the markets. The market prices of the leaf lettuces dynamically change day by day due to various environmental conditions, and the selling prices are increased if the delivery timing is fit to the date with high prices of the lettuces. Therefore, a suitable production plans are required to deliver the lettuces to the high price markets.

As regards the electric power supply, two types of supply systems are considered. They are, conventional electric power suppliers and electric power markets. The plant factories get most of the required electirc powers from the conventinal suppliers and a part of the electirc powers from the markets to decrease the procurement costs.

The following three issues will be discussed in the paper to manage the plant factories based on the vegetable markets and the electirc power markets.

(1) Production cost analysis of plant factories,

(2) Production planning of plant fatories based on vegetable market prices, and

(3) Purchasing electirc powers from electirc power markets

\section{Production Cost Analysis of Plant Factories}

The production costs of the vegetables produced in the plant factories are classified in to following items. 
(1) Construction costs of plant factories,

(2) Machinery costs of plant factories, such as pallets to seed vegetables, conveyers to transport the pallets, and devices to pick up the grown-up vegetables,

(3) Lighting source costs to give required photon flux density of the vegetables,

(4) Air-conditioning device costs to keep the environments in the plant factories, such as temperature and humidity,

(5) Running costs for the electricity required to operate the plant factories, and

(6) Other running costs.

The individual cost items are investigated based on the documents and data in the web-sites to estimate the production costs of one piece of the vegetables. The cost items considered here include such items as the construction costs of the plant factory buildings for an unit area, the conveyer costs for an unit length, the lighting device costs for the fluorescent lights and/or LED lights required to cultivate the vegetables, the air-conditioning costs to remove an unit kWh heat, and the power purchasing costs for an unit kWh.

The cost items are analyzed and a set of formulas are developed to estimate the production costs for the individual pieces of the vegetables. By applying the formulas, the production costs for the leaf lettuces are estimated for the cases of the fluorescent lights and the LED lights. For an example, Eq. (1) gives the photon flux requirement of the lighting sources to produce the vegetables, which is one of the most important formulas for designing the plant factories.

$$
P F=P F D \times S_{p} \times V_{\text {all }} \times \eta_{L}
$$

where,

$P F\left[\mu \mathrm{mol} \mathrm{s}{ }^{-1}\right]$ : Total photon flux required in the plant factories.

$P F D\left[\mu \mathrm{mol} \mathrm{m} \mathrm{m}^{-2} \mathrm{~s}^{-1}\right]$ : Photon flux density required to the lighting sources to cultivate the vegetables.

$S p\left[\mathrm{~m}^{2}\right]$ : Areas which the individual vegetables occupy.

$V_{\text {all }}$ : Total number of vegetables in the plant factories.

$\eta_{L}$ : Efficiency of the lighting sources.

The numbers of the lighting sources are estimated by applying Eq. (1), and the capacity and the electric powers of both the lighting sources and the air-conditioning systems are estimated based on the numbers and the electric powers of the lighting sources.

The basic specification of the pant factories considered here is summarized in Table 1 , based on the experimental plant factory in Osaka Prefecture University. Table 2 shows the specification of the leaf lettuces produced in the experimental plant factories. Whole plans of the plant factories for both fluorescent lights and the LED lights have been designed based on the specifications, and the production costs are estimated for individual pieces of the lettuces. 
Table 1 Specification of a plant factory

\begin{tabular}{|c|c|}
\hline Daily production & 5,000 [pieces] \\
\hline Capacity & 25,000 [pieces] \\
\hline Lighting sources & Fluorescent lights or LED \\
\hline Efficiency of light & 80 [\%] \\
\hline
\end{tabular}

Table 2 Specification of a leaf lettuce

\begin{tabular}{|c|c|}
\hline Cultivation period & $25[$ days $]$ \\
\hline Photon flux density & $150\left[\mu \mathrm{mol} \mathrm{m} \mathrm{s}^{-1}\right]$ \\
\hline
\end{tabular}

Table 3 Summary of production costs for plant factories (Yen/Piece)

\begin{tabular}{|c|c|c|}
\hline & $\begin{array}{c}\text { Plant factories } \\
\text { equipped with fluores- } \\
\text { cent lights }\end{array}$ & $\begin{array}{c}\text { Plant factories } \\
\text { equipped with LED }\end{array}$ \\
\hline Lighting source & 9.88 & 58.9 \\
\hline Air conditioning & 14.2 & 2.19 \\
\hline Construction & 11.0 & 11.0 \\
\hline Equipment & 2.78 & 2.78 \\
\hline Seeds, water, etc. & 6.10 & 6.10 \\
\hline Electric power & 88.4 & 28.4 \\
\hline Total Cost & 132 & 109 \\
\hline
\end{tabular}

The estimated costs are summarized in Table 3 for the plant factories equipped with the fluorescent lights and ones with LEDs. The estimated costs are roughly same with the production costs of the existing plant factories. The differences of the cost items between two light sources are also roughly same as the existing plant factories. In the case of ones equipped with LED lights, the lightning device cost is high, but the airconditioning cost and the electricity costs are low, due to high efficiency and low energy consumption of the LED lights against the fluorescent lights.

\section{Production Planning and Purchasing of Electric Power}

\subsection{Estimation of Wholesale Market Prices}

A suitable production plans for the Plant factories are required to produce and to supply the vegetables in suitable timing to the markets. A production planning method is discussed in the section based on the market price estimation of the lettuces.

The market prices of lettuces are changing day by day due to surrounding conditions such as seasons, whether, and climate [4]. Many research works have been carried out to forecast the vegetable market prices by applying the ARIMA model of the time series analysis and the Neural Network model [5-6]. However, it is required to establish long-term forecasting methods for the production planning, due to the long lead time in the plant factories. Therefore, the correlations between the wholesale market prices in Tokyo and the various parameters of the weather such as temperature, humidity, and so on, were firstly analyzed, and it was found that the lowest temperature 


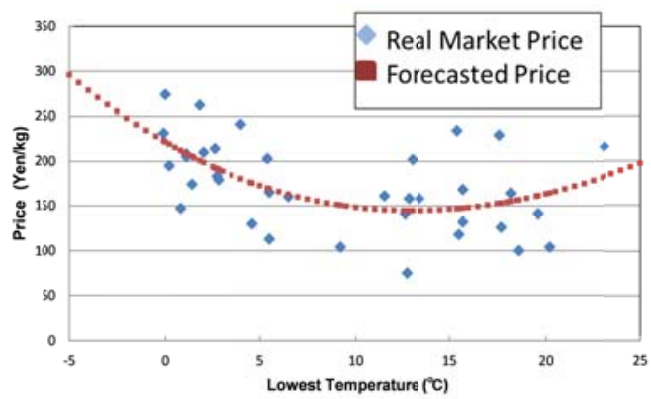

Fig. 2. Relationships between real market prices and forecasted pricies

has highest correlations with the lettuce prices. A genetic programming (GP) based system has been developed to forecast the market prices of the lettuces based on the time series data of both the market prices and the lowest temperature. The formulas to forecast the market process are generated by applying the GP method based on the training data of the prices in the real markets and the lowest temperature in every month for 8 years. Equation (2) shows the obtained formula represented by the polynomial for forecasting the prices.

$$
E P=\sum_{k=0}^{n} k_{n} L T^{n}
$$

where,

EP: Market prices of leaf lettuces

$L T$ : Lowest temperature

$k_{n}$ : Constants

The formulas are applied to the forecast of the market prices for 3 years other than the training data for 8 years. Figure 2 shows the evaluation results, which give the relationships between the real wholesale market prices and the forecasted prices. Equation (2) obtained here is applied to the production planning of the plant factories to deliver the vegetables to the markets at suitable timing.

\subsection{Production Planning Based on Market Prices}

A production planning method is proposed based on the forecasting system of the wholesale market prices. This method selects a suitable vegetable to be cultivated in daily operations.

Two types of plant factories are considered in the present research. They are,

(1) Factory A produces only leaf lettuces, and

(2) Factory B has the capability of producing both leaf lettuces and another vegetable called $\beta$.

The following items are assumed for the ease of production planning. 
(a) The factory $\mathrm{B}$ has the equipment to produce two vegetables and the production costs are higher than ones of the factory A,

(b) Both the leaf lettuces and the vegetable $\beta$ have same cultivation period of 25 days,

(c) The vegetable $\beta$ can be sold by the price same as the production costs, and

(d) The retail vegetable market prices are higher than the wholesale market prices in either 3 , 3.5 or 4 times.

The following procedure is proposed to carry out production planning.

STEP 1: Forecasting of lowest temperature and wholesale market prices

The lowest temperature of 25 days after are firstly forecasted based on the weather forecast and the wholesale market prices of the lettuces are also estimated by applying Eq. (2) . The cultivation period in the plant factories is set to be 25 days, and the production planning requires the forecast of the market prices of 25 days after, in order to select the cultivation operations in the next day.

STEP2: Selection of vegetables to be cultivated in the nest day

(1) Plant factory A

The production planning system for the plant factory A selects the one of the following tow operations for the next day.

a) Cultivating lettuces, if the forecasted price is higher than the production costs, or

b) No cultivation, if the forecasted price is lower than the production costs.

c)

(2) Plant factory B

The production planning system of factory B selects one the following two operations for the next day.

a) Cultivating lettuces, if the forecasted price is higher than the production costs, or

b) Cultivating vegetable $\beta$, if the forecasted price is lower than the production costs.

In the plant factory $B$, the vegetable $\beta$ is cultivated to avoid the loss of the running cost, for the cases that the forecasted lettuce price is lower than the production costs. However, the production cost of the plant factory B is higher than one of the plant factory A, due to the additional production equipment for two types of vegetables.

\subsection{Purchasing of electric power from market}

As regards the electric power supply, two suppliers are considered in the research. One is the conventional electric power suppliers, which provide the electricity by the fixed prices based on the long term contracts. Another is electric power markets, in which the amount of power supply and the prices are determined based on the daily supplies and demands, such as Nord Pool in EU and JEPX (Japan Electric Power eXchange) in Japan [7]. Figures 3 and 4 show a structure of the electric power markets and the relationships between the balanced prices and the amount of the electric power supplied to the markets, respectively.

When the vegetables to be cultivated in the next day are fixed, the total electric power requirement is estimated and the demands to the electric power market are determined. The demand of the plant factory is sent to the market, and the market determines the amount of electric power and its price in the next day. 


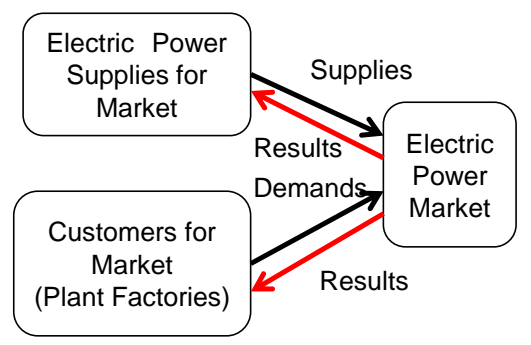

Fig. 3. Electric Power Market

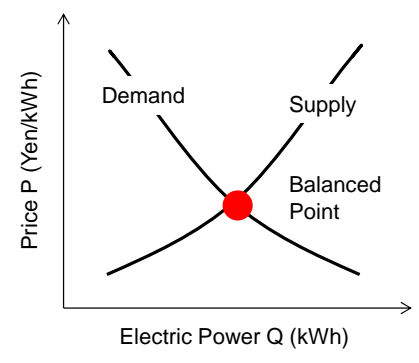

Fig. 4. Market mechanisms

\section{Simulation Results}

One year simulations of both the factories A and B have been carried out by applying the forecasted prices and the real prices of the lettuces from Jan. to Dec., 2010. As regards the electric power market, a statistical simulation model is proposed, which include 10 suppliers and 20 customers including the plant factory. The daily supplies and demands of the individual suppliers and customers are selected randomly in the simulations.

Figure 5 shows the simulation results about the profits of the plant factories A and B. The profits of both the factories depend on the market price of the lettuce. When the market price is low, the combined production of the factory B reduces the loss by producing the vegetable $\beta$. The simple production of the factory A gets the higher profit in the case of high market price. The combined production in factory B is not so efficient, if the market price is high and stable. The production volumes in factory B is summarized in Fig. 6. The percentage of the lettuce is high in the winter seasons, since the market price is high due to low temperature, as shown in Fig. 3. The simulations have been carried out for five times due to the statistical characters of the market price forecasting. The individual lines in Fig. 6 show the different simulation results, but all the tendency are almost same.

\section{Conclusions}

A plant factories and its production planning system are discussed in the paper. The followings are concluded.

(1) The production cost items are considered to plan and to estimate the production costs of individual piece of leaf lettuces, based on the investigations of the experimental plant factories in Osaka Prefecture University and related documents.

(2) A genetic programming (GP) based method is proposed to forecast the future prices of the lettuces, since the long lead time of 25 days are required for cultivating the lettuces.

(3) A production planning system for the plant factories is proposed to select a suitable vegetable to be cultivated in every day operations, aimed at increasing the profits and decreasing the operation costs. 


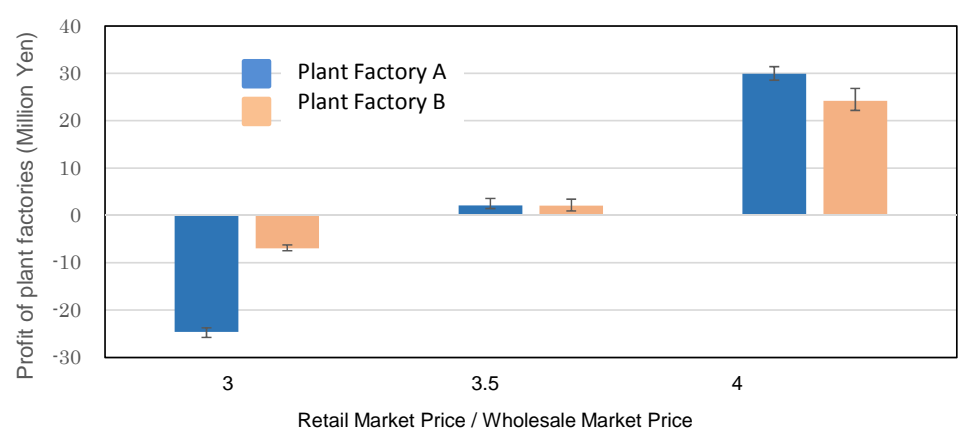

Fig. 5. Profit of plant factory

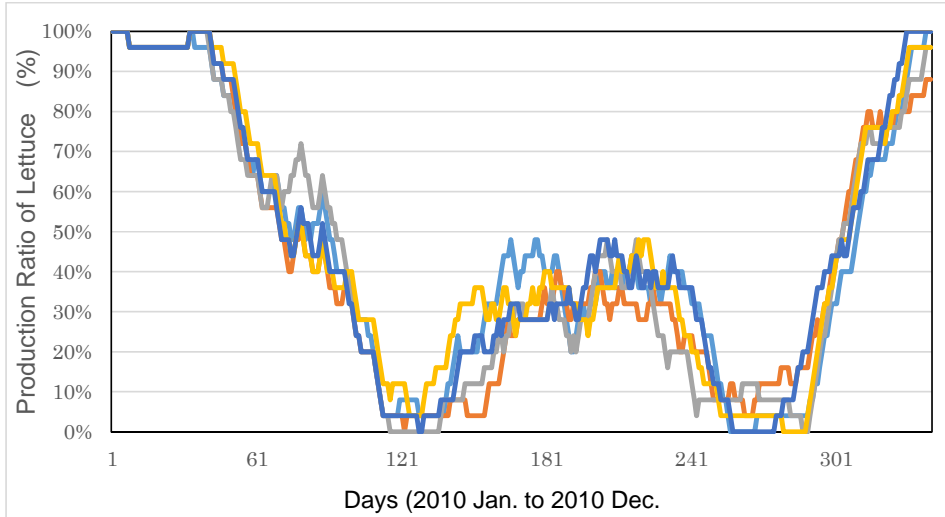

Fig. 6. Production volumes of lettuce in plant factory B

\section{Rreferences}

[1] Takatsuji. M., 2007, Fully Controlled and Closed Plant Factory, Ohmsha Ltd., pp63-65 (in Japamese)

[2] Outline of Facilities (R\&D Center for the Plant Factory), (http://www.plantfactory.21c.osakafu-u.ac.jp/english/index.html)

[3] Takatsuji. M. ,Mori.Y, 2011, LED Plant factory, Nikkan Kogyo Shimbun Ltd., pp10-27 (in Japanese)

[4] Tokyo Metropolitan Central Wholesale Market (http://www.shijou.metro.tokyo. jp/torihiki/) (in Japanese)

[5] Shukla M. and Jharkharia S., 2011, Applicability of ARIMA Models in Wholesale Vegetable Market, Proc. of the 2011 International Conference on Industrial Engineering and Operations Management, pp1125-1130.

[6] Nasira, G.M. and Hemageetha, A., 2012, Forecasting Model for Vegetable Price Using Back Propagation Neural Network, Int. J. of Computational Intelligence and Informatics, Vol.2, No.2, pp110-115.

[7] Japan Electric Power eXchange (http://www.jepx.org/english/aboutus/index. html) 